\title{
Systems Analysis and Structural Design of an Unpressurized Cargo Delivery Vehicle
}

\author{
K. Chauncey Wu (1), Jonathan N. Cruz (2), Jeffrey Antol (3) and Washito A. Sasamoto (4) \\ NASA Langley Research Center, Hampton, VA 23681-2199
}

\begin{abstract}
The International Space Station will require a continuous supply of replacement parts for ongoing maintenance and repair after the planned retirement of the Space Shuttle in 2010. These parts are existing line-replaceable items collectively called Orbital Replacement Units, and include heavy and oversized items such as Control Moment Gyroscopes and stowed radiator arrays originally intended for delivery aboard the Space Shuttle. Current resupply spacecraft have limited to no capability to deliver these external logistics.

In support of NASA's Exploration Systems Architecture Study, a team at Langley Research Center designed an Unpressurized Cargo Delivery Vehicle to deliver bulk cargo to the Space Station. The Unpressurized Cargo Delivery Vehicle was required to deliver at least $13,200 \mathrm{lb}$ of cargo mounted on at least 18 Flight Releasable Attachment Mechanisms. The Crew Launch Vehicle design recommended in the Exploration Systems Architecture Study was used to launch one annual resupply flight to the International Space Station.

The baseline vehicle design developed here has a cargo capacity of $16,000 \mathrm{lbs}$ mounted on up to 20 Flight Releasable Attachment Mechanisms. Major vehicle components are a $5.5 \mathrm{~m}$-diameter cargo module containing two detachable cargo pallets with the payload, a Service Module to provide propulsion and power, and an aerodynamic nose cone. To reduce cost and risk, the Service Module is identical to the one used for the Crew Exploration Vehicle design.
\end{abstract}

\section{Nomenclature}

$\begin{array}{ll}\text { APAS } & \text { Androgynous Peripheral Attachment System } \\ \text { CEV } & \text { Crew Exploration Vehicle } \\ \text { CLV } & \text { Crew Launch Vehicle } \\ \text { CM } & \text { Center of mass } \\ \text { COTS } & \text { Commercial Orbital Transportation Services } \\ \text { CBM } & \text { Common Berthing Mechanism } \\ \text { CMG } & \text { Control Moment Gyroscope } \\ \text { ESAS } & \text { Exploration Systems Architecture Study } \\ \text { ESP-2 } & \text { External Stowage Platform-2 } \\ \text { EVA } & \text { Extravehicular activity } \\ \text { FRAM } & \text { Flight Releasable Attachment Mechanism } \\ \text { FRGF } & \text { Flight Releasable Grapple Fixture } \\ \text { g } & \text { Acceleration due to gravity, 32.2 ft/s } 2 \\ \text { ISS } & \text { International Space Station } \\ \text { kIb } & 1000 \text { lbs } \\ \text { LAS } & \text { Launch Abort System } \\ \text { LIDS } & \text { Low Impact Docking System } \\ \text { MMOI } & \text { Mass moment of inertia }\end{array}$

(1) Aerospace Engineer, Vehicle Analysis Branch, SACD. Mail Stop 451.

(2-4) Aerospace Engineer, Space Mission Analysis Branch, SACD. Mail Stop 462. 


$\begin{array}{ll}\text { MT/MBS } & \text { Mobile Transporter/Mobile Base System } \\ \text { Nx } & \text { Axial line load, Ib/in. } \\ \text { nmi } & \text { Nautical mile(s) } \\ \text { ORU } & \text { Orbital Replacement Unit } \\ \text { PAS } & \text { Payload Attach System } \\ \text { PDGF } & \text { Power Data Grapple Fixture } \\ \text { P3 } & \text { ISS truss segment, port side number 3 } \\ \text { SACD } & \text { Systems Analysis and Concepts Directorate } \\ \text { SM } & \text { Service Module } \\ \text { SSRMS } & \text { Space Station Remote Manipulator System } \\ \text { S3 } & \text { ISS truss segment, starboard side number 3 } \\ \text { UCDM } & \text { Unpressurized Cargo Delivery Module } \\ \text { UCDV } & \text { Unpressurized Cargo Delivery Vehicle }\end{array}$

\section{Introduction}

After the planned retirement of the Space Shuttle in 2010, there will still be a need to deliver new Orbital Replacement Units to the International Space Station in its approximately 240-nmi, 51.6-degree inclination orbit. These ORUs are existing line-replaceable units for continuing on-orbit maintenance and repair of the ISS, and include both massive and oversized items originally designed for delivery to the ISS aboard the Space Shuttle. Examples of these ORUs include the Control Moment Gyroscopes, HighPressure Oxygen Tanks, and stowed radiator arrays. With the exception of the Space Shuttle, existing resupply spacecraft like the $\mathrm{H}$-II Transfer Vehicle cannot carry the largest ORUs to the ISS, while the Automated Transfer Vehicle, Soyuz and Progress vehicles cannot deliver any external logistics (Ref. 1).

In June 2005, the Systems Analysis and Concepts Directorate at the NASA Langley Research Center was tasked with performing a conceptual design study to develop an Unpressurized Cargo Delivery Vehicle that would support the ISS program in the post-2010 time frame. This work was initially done as part NASA's 90-day Exploration Systems Architecture Study (Ref. 2). This paper presents an overview of the UCDV system requirements, vehicle configuration, concept of operations, and structural design and layout that were performed for both the ESAS and during a follow-on study conducted later in 2005.

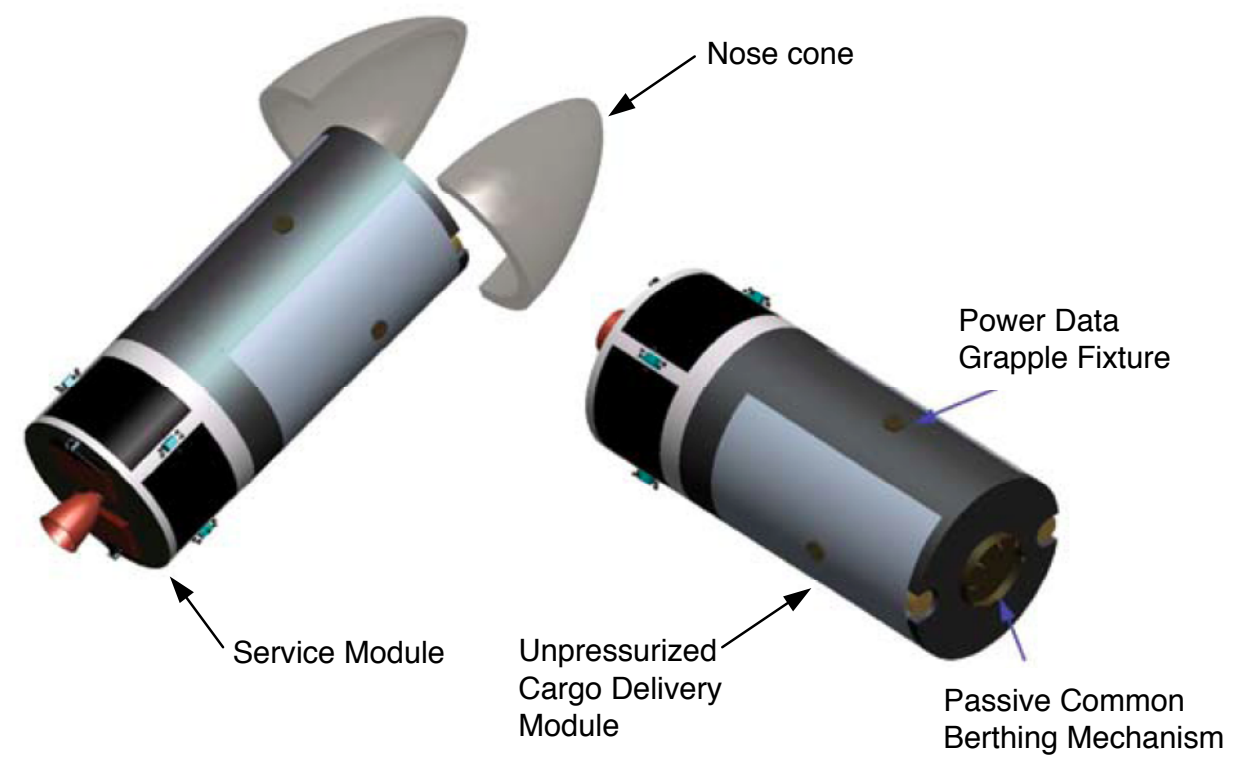

Figure 1. Unpressurized Cargo Delivery Vehicle 


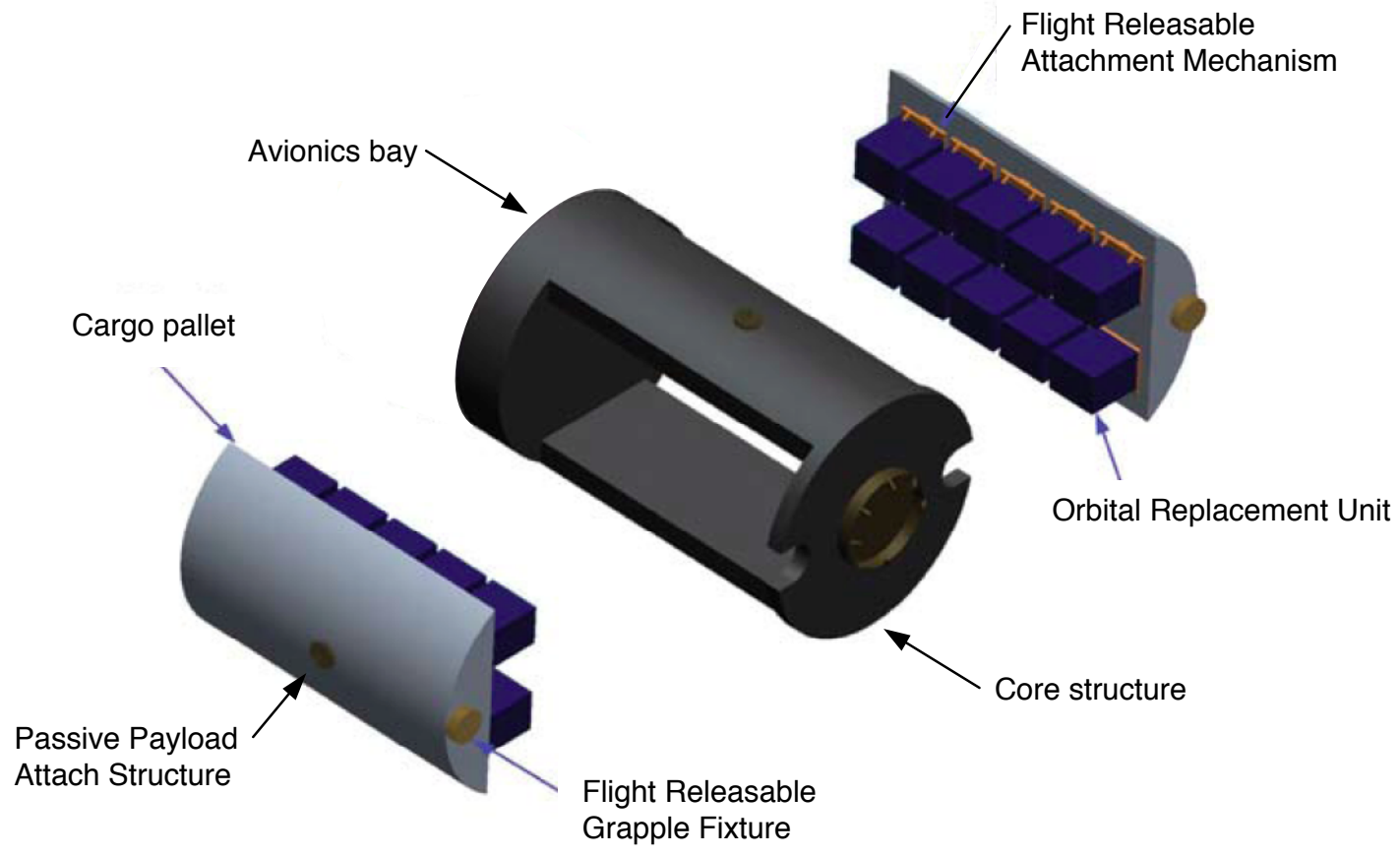

Figure 2. Unpressurized Cargo Delivery Module.

Major components identified for the UCDV (Figure 1) are the Unpressurized Cargo Delivery Module (Figure 2) comprised of a core structure and two detachable cargo pallets holding the ORUs, an aerodynamic nose cone, and a Service Module to provide on-orbit propulsion and power for the UCDM. The attached SM is assumed to be identical to the design used for the Crew Exploration Vehicle, thus reducing the overall system development schedule, cost and risk. However, the amount of propellant required for the UCDV to reach the ISS is substantially less than necessary for the crewed Lunar mission used to size the SM tankage. To maximize the cargo capacity for the unpressurized cargo resupply mission, only the minimum amount of propellant required for ISS rendezvous and later disposal is carried on the UCDV.

\section{System Requirements}

System design specifications called for the UCDV to deliver a minimum of $13,200 \mathrm{lb}$ of cargo to the ISS, with the ORUs mounted on at least 18 Flight Releasable Attachment Mechanisms (Ref. 3). The UCDV concept of operations developed here called for one resupply flight for unpressurized cargo per year to the ISS atop a Crew Launch Vehicle (designated as LV 13.1 in Ref. 2). This launch vehicle, shown in Figure 3 with a CEV payload, 4-segment Solid Rocket Booster first stage and Space Shuttle Main Engine-powered second stage, can deliver an estimated payload of 50,480 lbs to a 51.6-degree, $30 \times 160$ nmi ISS transfer orbit. A Launch Abort System is not required since the UCDV is uncrewed. Removal of the $9300 \mathrm{lb}$ LAS will also improve the CLV ascent performance since the LAS does not need to be carried to its $212,000 \mathrm{ft}$ jettison altitude. A rough estimate for the increased payload resulting from removal of the LAS is (9300 lb)/7 or $1329 \mathrm{lbs}$, but this additional performance is not credited to the CLV for this study.

The FRAM system (Figure 4) provides a standard structural and mechanical interface for accommodating cargo during transport to, stowage and handling on the ISS. The FRAM is comprised of active and passive components, where the ORU is attached to the Active FRAM and the Passive FRAM components are fitted to the UCDV structure. The FRAMs are also designed to be compatible with both human and robotic handling aboard the ISS. For this study, nominal dimensions of an equivalent cargo unit comprised of an Active FRAM and ORU are $36 \times 47 \times 49$ inches $\left(48 \mathrm{ft}^{3}\right)$, with a nominal mass of $800 \mathrm{lbs}$. 
However, the actual ORUs vary greatly in both mass and volume, and range from very small ones that require only a fraction of a cargo unit's mass and volume, to larger ones such as a CMG which, at $600 \mathrm{lbs}$ mass and $65 \mathrm{ft}^{3}$ volume, would need to be book-kept as two cargo units since its volume (but not its mass) exceeds the reference value. The largest actual ORU is the stowed radiator array, with a mass of $2473 \mathrm{lbs}$ and a volume of $289 \mathrm{ft}^{3}$.
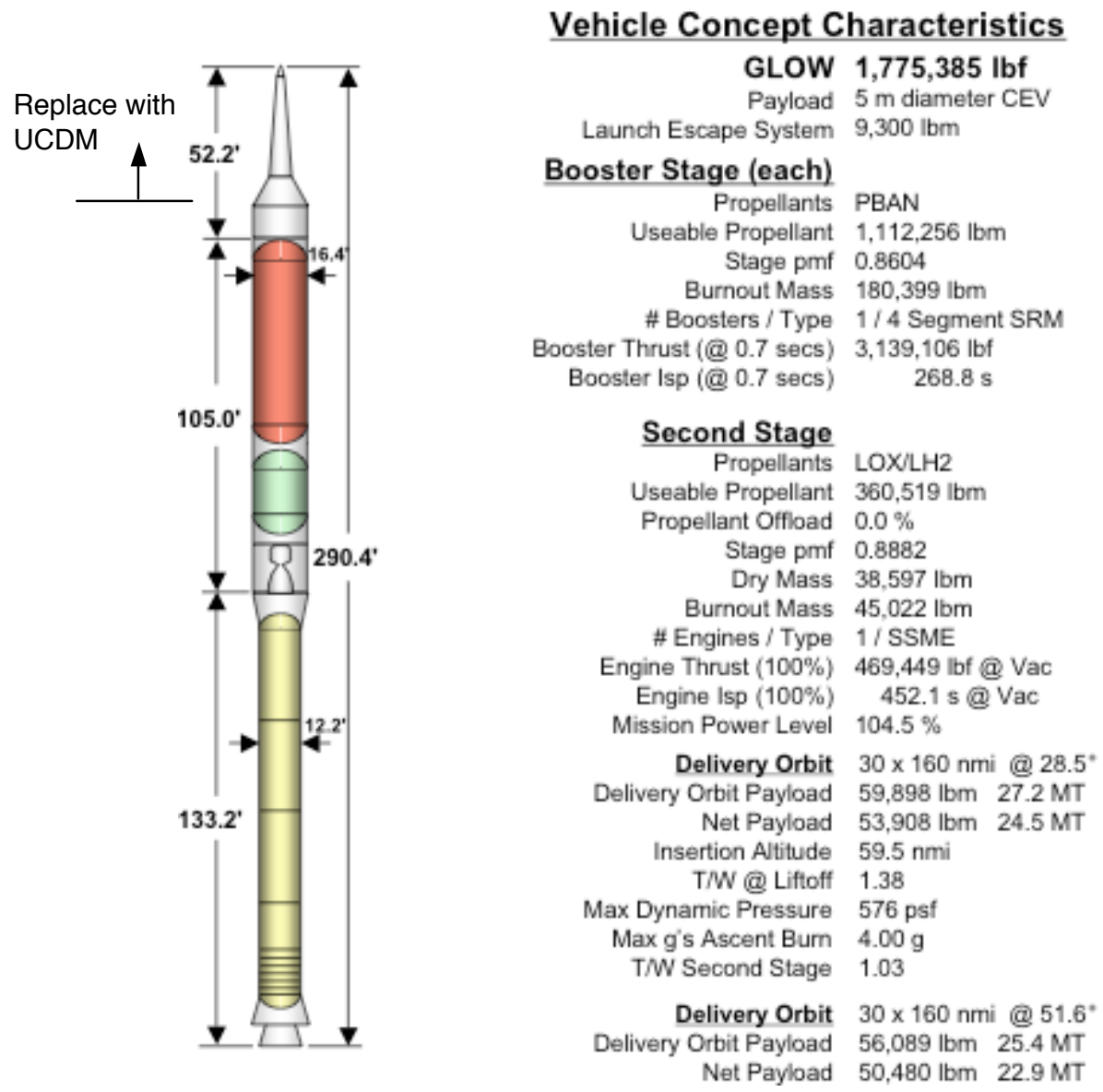

Figure 3. Crew Launch Vehicle.

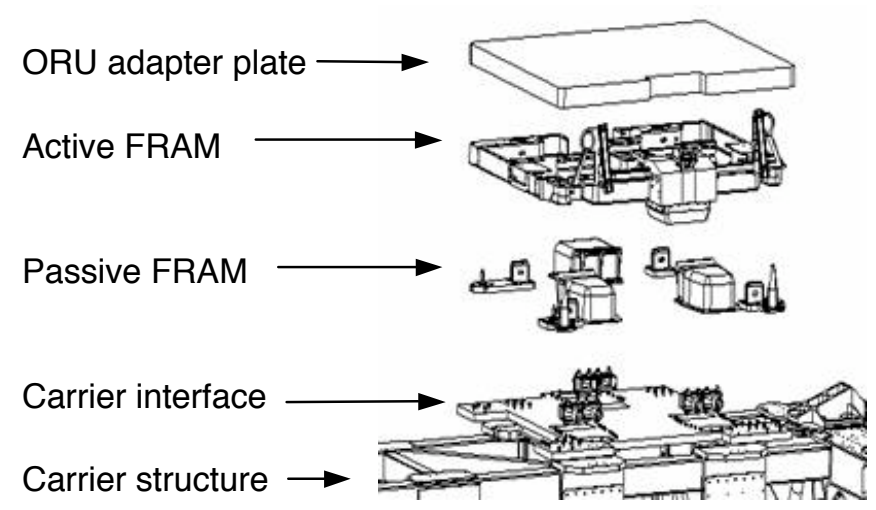

Figure 4. FRAM system.

American Institute of Aeronautics and Astronautics 
To illustrate their variability, size definitions for the large and medium ORUs carried aboard the UCDV are presented. A medium ORU is one that is FRAM-compatible with a mass between 200 and $500 \mathrm{lbs}$. The average mass of the approximately 20 known medium ORUs is $283 \mathrm{lbs}$, with an average volume of $18 \mathrm{ft}^{3}$. A large ORU is either greater than $500 \mathrm{lbs}$ mass, or requires unique flight support equipment to mount to the carrier structure. The average mass of the approximately 30 large ORUs is $621 \mathrm{lbs}$, with an average volume of $82 \mathrm{ft}^{3}$. The variability of these data illustrates the scope of issues that must be addressed during development of a single UCDV design that must accommodate at least 18 cargo units. To handle the logistics needs of the ISS and the wide range of dimensions and masses of the ORUs, the cargo manifests of each UDCV flight must be carefully tailored to meet pallet mass and stowage volume constraints, as well as requirements for cargo storage and handling aboard the ISS. However, accommodation of actual ORU combinations was not addressed during this study.

\section{Vehicle Configuration}

During the ESAS, the diameters of both the CEV and CLV second stage varied as the different concepts were refined. At the time of this study, the diameter of the CEV for the ISS missions was 5.5 meters (Ref. 2). Since the UCDV used the same SM as the CEV, its outer mold line was also sized at $5.5 \mathrm{~m}$ in diameter. Several "tower" UCDM configurations, shown as end views in Figure 5, were developed and evaluated during the early stages of this study. The UCDMs in these concepts each contained (from left to right) a total of 20,20 and 18 cargo units attached to an approximately $2 \mathrm{~m}$-diameter central structure that was, respectively, five, four and three cargo units in length (where each cargo unit was 4 feet long). The entire tower and attached cargo units were then completely enclosed in a full-length disposable payload fairing to protect the cargo during ascent, and an integral nose cone was also fitted to streamline the vehicle.

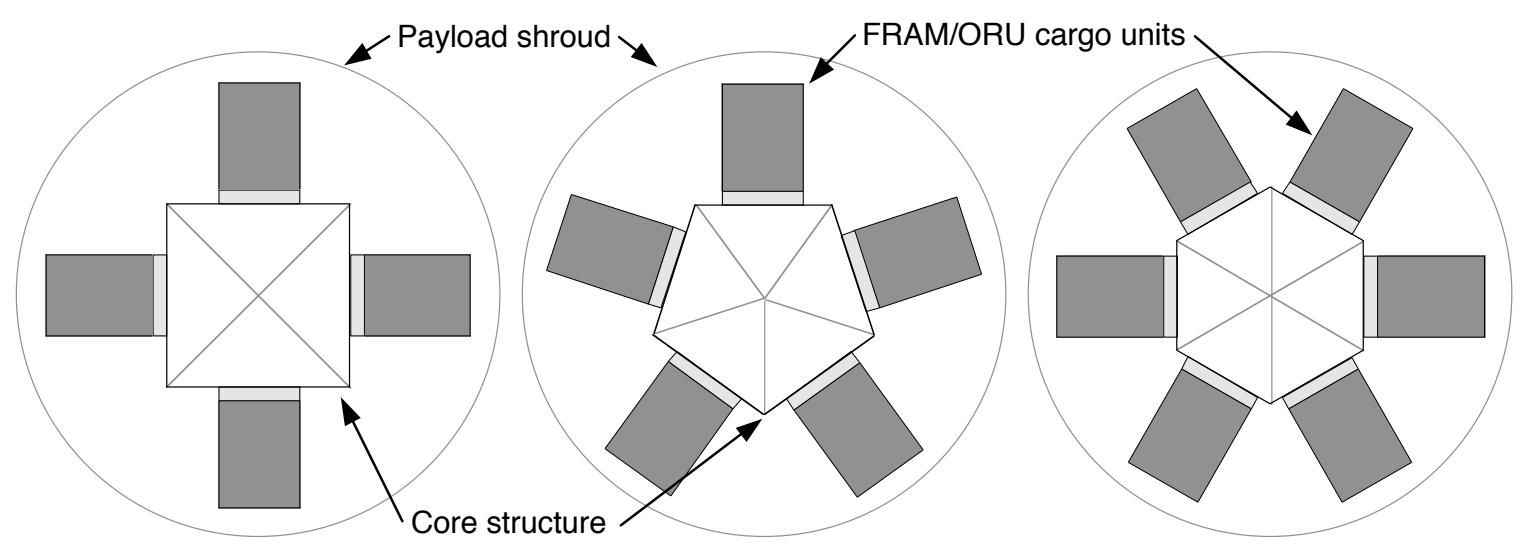

Figure 5. End views of preliminary UCDM designs.

Concerns raised regarding these designs included their low packaging efficiency within the fairing, as well as their capability to accommodate certain oversized ORUs, such as stowed radiators, which required attachment to several coplanar FRAMs. The notional concept of operations for these UCDV designs called for the vehicle to be berthed to the ISS using a Passive Common Berthing Mechanism (Ref. 4). The individual ORUs would then be removed from their FRAMs and either stowed or installed on the ISS. However, these cargo transfer operations were expected to take longer than the 30-day maximum time that the UCDV was allowed to occupy the Active CBM port on the ISS. In addition, the tower configuration's low bending stiffness and natural frequency both atop the SM and when attached to the ISS, as well as possible conflicts with ISS requirements on mass moments of inertia and center of mass for attached vehicles, were recognized as posing problems for the implementation of these designs. These factors led to reevaluation of these proposed designs, and finally led to development of the UCDM configuration shown in Figures 1 and 2. 


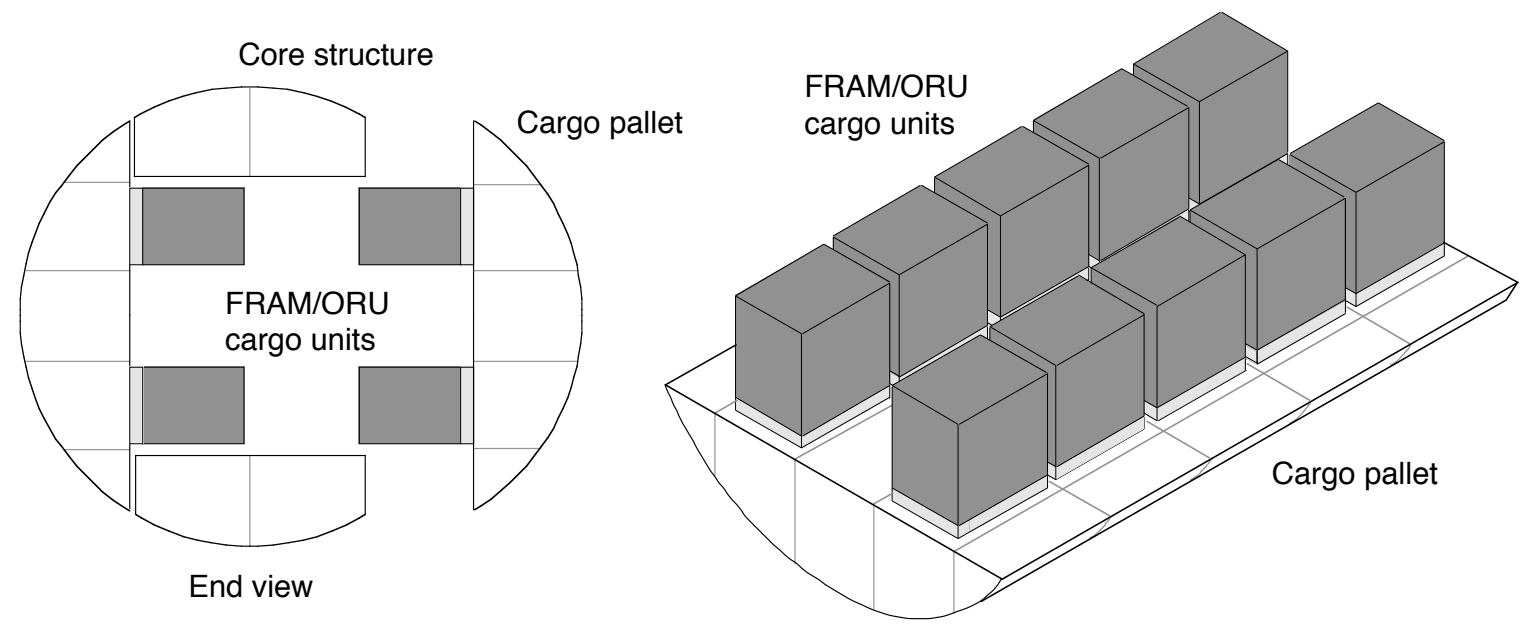

Figure 6. UCDM configuration with $(2 \times 5)$ pallet.

For the selected UCDM pallet design shown in Figure 6, the vehicle outer mold line was expanded out to the full $5.5 \mathrm{~m}$ diameter of the attached SM. This eliminated the separate payload fairing and allows use of the fairing dynamic envelope for the primary structure. This arrangement does incur a slight performance penalty, since the launch vehicle is now carrying the "fairing" mass all the way to the ISS orbit instead of jettisoning it at the same time as the nose cone. However, all of the load-bearing structural elements in this arrangement are now located towards the maximum diameter of the UCDM, where they provide structural benefits for this design like increased bending stiffness.

The UCDM core structure is comprised of two deep box beams attached to two disk-shaped end caps. The avionics bay in the aft end cap contains flight electronics, batteries and other subsystems, as well as providing the interfaces with the SM. The forward end cap supports both the Passive CBM for berthing to the ISS and the base of the nose cone. During launch, the two large UCDM cargo pallets shown in Figure 6 are mechanically connected along their edges to the UCDV core structure, thus forming a very stiff integrated configuration. After the UCDV is berthed to the ISS, these mechanical latches are released remotely to allow the pallets and attached cargo units to be removed from the UCDV. As a contingency, these latching devices must also be manually releasable by astronauts during an extravehicular activity, since the FRAMs are not accessible through the Passive CBM. More detailed structural design effort is needed to help determine whether the pallets will transfer all of the ORU inertial loads and vehicle flight loads as shear through the latches into the core beams, or to share some of the load as compression through the pallet outer mold line and into the aft end cap.
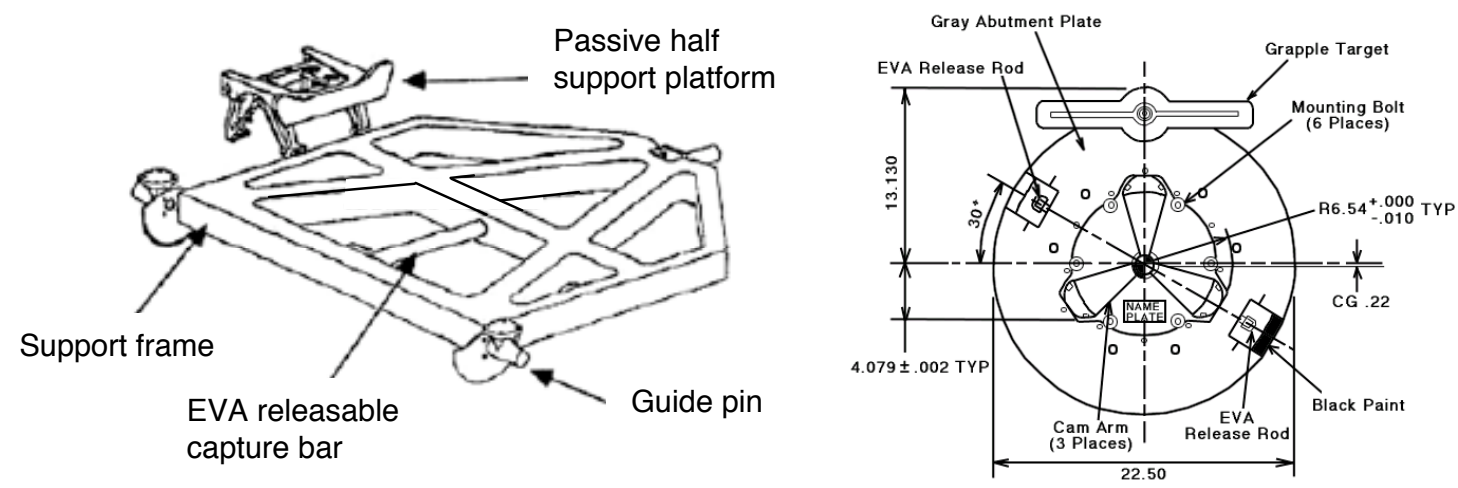

Figure 7a (left), 7b (right). Passive PAS and FRGF mechanisms. 
A total of 20 cargo units are stored on these two pallets, and each $(2 \times 5)$ pallet has two rows of five columns of cargo units separated by a 4-foot wide aisle for astronauts to reach the base of the FRAMs during EVA. This arrangement allows excellent access for removal of the ORUs using EVA or telerobotic systems, while still allowing maximum flexibility for stowage and transport of large and irregularly shaped cargo elements. A Passive Payload Attach System (see Figure 7a) and a Flight Releasable Grapple Fixture (Figure $7 \mathrm{~b}$ ) are also mounted on each pallet to provide for attachment to and transport around the ISS structure. Further details of these mechanisms are provided in Reference 4.

After completion of the ESAS activity, the UCDV design was revisited to determine if more efficient vehicle configurations were possible, and to account for new requirements, constraints and operational considerations. Relaxation of the EVA access requirement and subsequent use of the central aisle to carry additional cargo allowed a more compact pallet arrangement of three rows of four columns of cargo units (see Figure 8$)$ to be evaluated. This $(3 \times 4)$ pallet configuration would increase the total cargo capacity to a maximum of 24 cargo units and also reduce the overall UCDM length, resulting in better packaging efficiency and a higher natural frequency atop the CLV. The structural mass of the pallets and core beams could also be reduced by about 20 percent or 1650 lbs (using a mass estimate of 8268 lbs reported in Table 1 for the long pallets and core beams of the ESAS design), since they are now shorter than the original design in Figure 6 by one FRAM unit. However, if four additional cargo units were carried, the cargo mass could increase by $3200 \mathrm{lbs}$, for a net increase of $1550 \mathrm{lbs}$ in the UCDM mass.
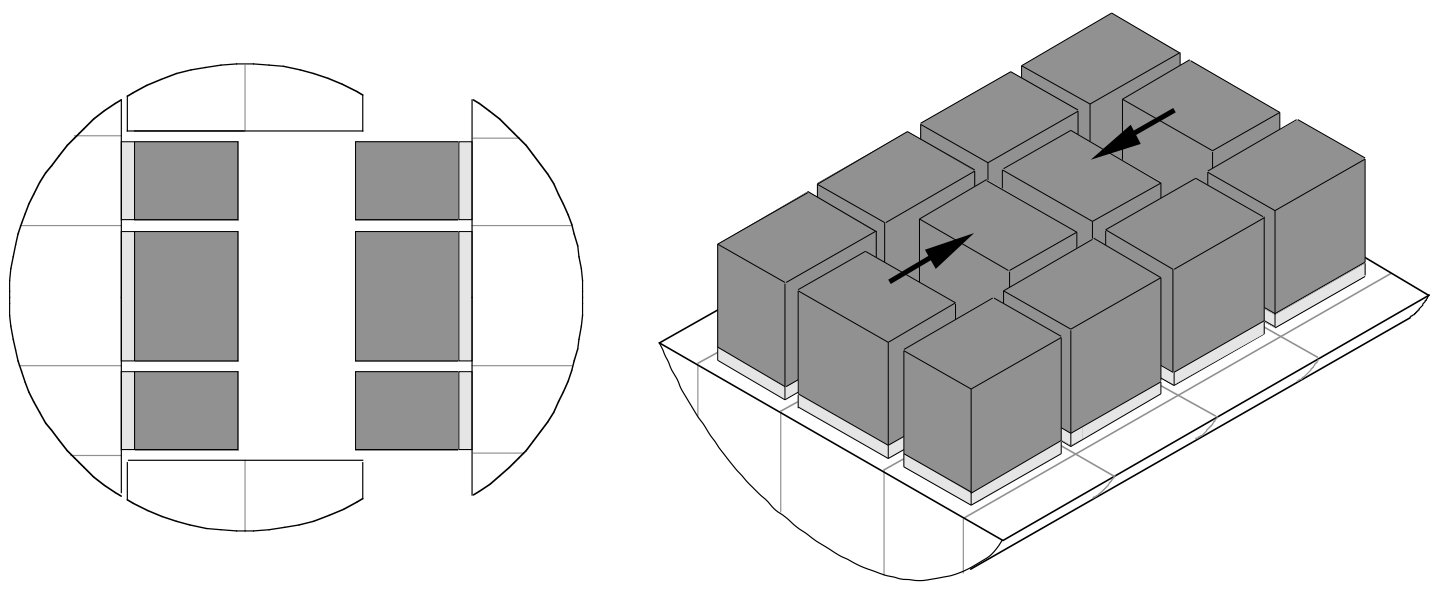

Figure 8. Alternate $(3 \times 4)$ pallet configuration.

The central column of cargo units in this pallet design must also be rotated by 90 degrees because the FRAM mechanism has a required direction for access to a stowed ORU (as indicated by the arrows in Figure 8). An additional constraint is then imposed on what can be stowed in the central two FRAM locations, since they are completely blocked in by surrounding cargo units. One solution would require positioning of lower-priority cargo on these central FRAMs, which could then be accessed only after the more urgently needed ORUs on the outboard locations are removed. Another possible concern with this pallet design is that reorientation of the central cargo units reduces the depth of the core beams on each side (compare Figures 6 and 8 ), resulting in a reduction in bending stiffness and natural frequency as well as the bearing area for attachment of the cargo pallets.

More detailed manifesting analyses with actual ORU masses and volumes must still be performed to determine the loaded pallet masses, MMOls and CMs while stowed aboard the ISS. If requirements on these quantities were to be violated by using the longer pallet design shown in Figure 8, then each large pallet could be further subdivided into two smaller $(3 \times 2)$ pallets (see Figure 9a) with three rows of cargo units in two columns. However, this arrangement would be more massive than the single $(3 \times 4)$ pallet, since each $(3 \times 2)$ pallet would require some additional structure as well as a separate FRGF and Passive PAS (253 lbs). In addition, various combinations (e.g., two long, one long and two short, or four short) of 
these pallets could be carried on the UCDV as dictated by ISS logistics requirements. However, operational penalties (e.g., increased number of payload mounting locations and separate transfer operations) are also incurred by increasing the number of pallets.

If necessary to save mass, the pallet design in Figure 8 could be shortened yet again to carry nine cargo units in three columns of three rows. This $(3 \times 3)$ pallet, shown in Figure 9b, would still meet the minimum requirement for the UCDV to deliver 18 cargo units to the ISS on each flight. The mass of the pallets and core beams of this shortened design could be as much as 40 percent less than the mass of the baseline design in Figure 6. Using the structural mass of $8268 \mathrm{lbs}$ noted above, the $(3 \times 3)$ pallet design below could save up to $3300 \mathrm{lbs}$ from the reduced pallet length, as well as $1600 \mathrm{lbs}$ from the reduced cargo capacity of this design (18 cargo units instead of 20).

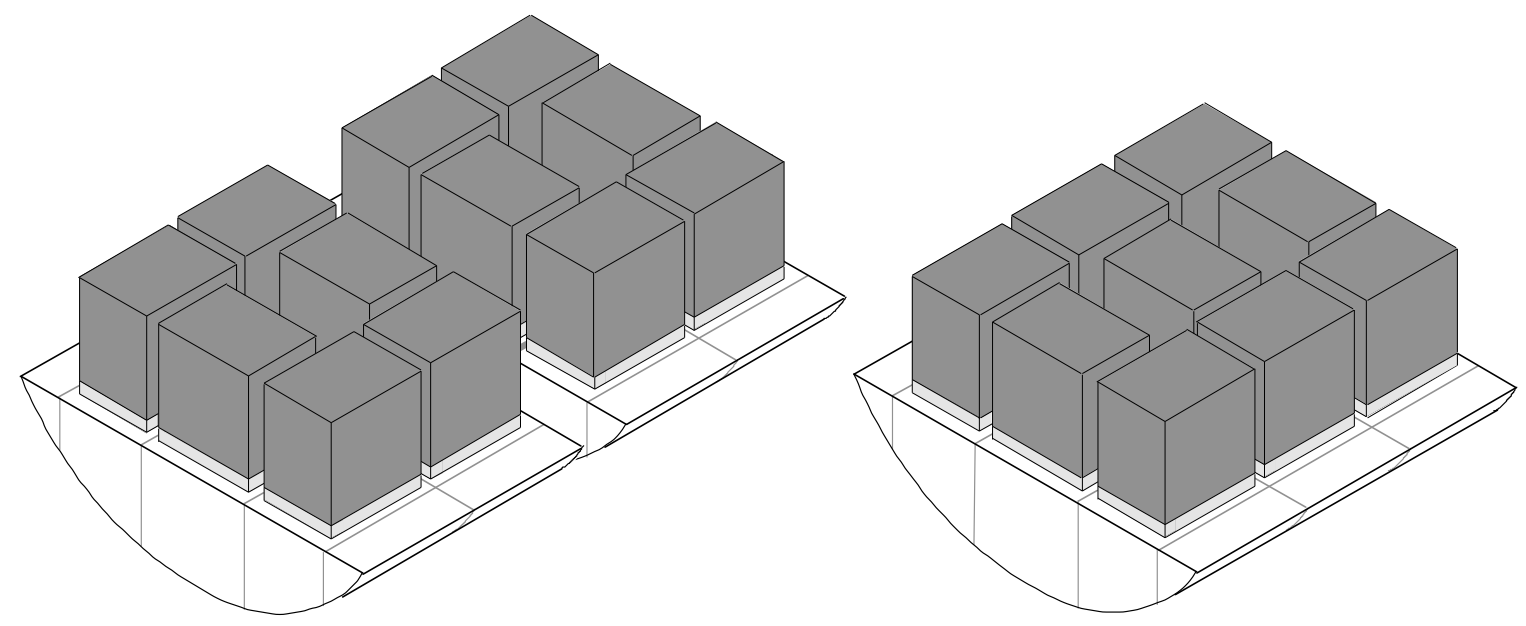

Figure 9a (left), 9b (right). Small pallet configurations.

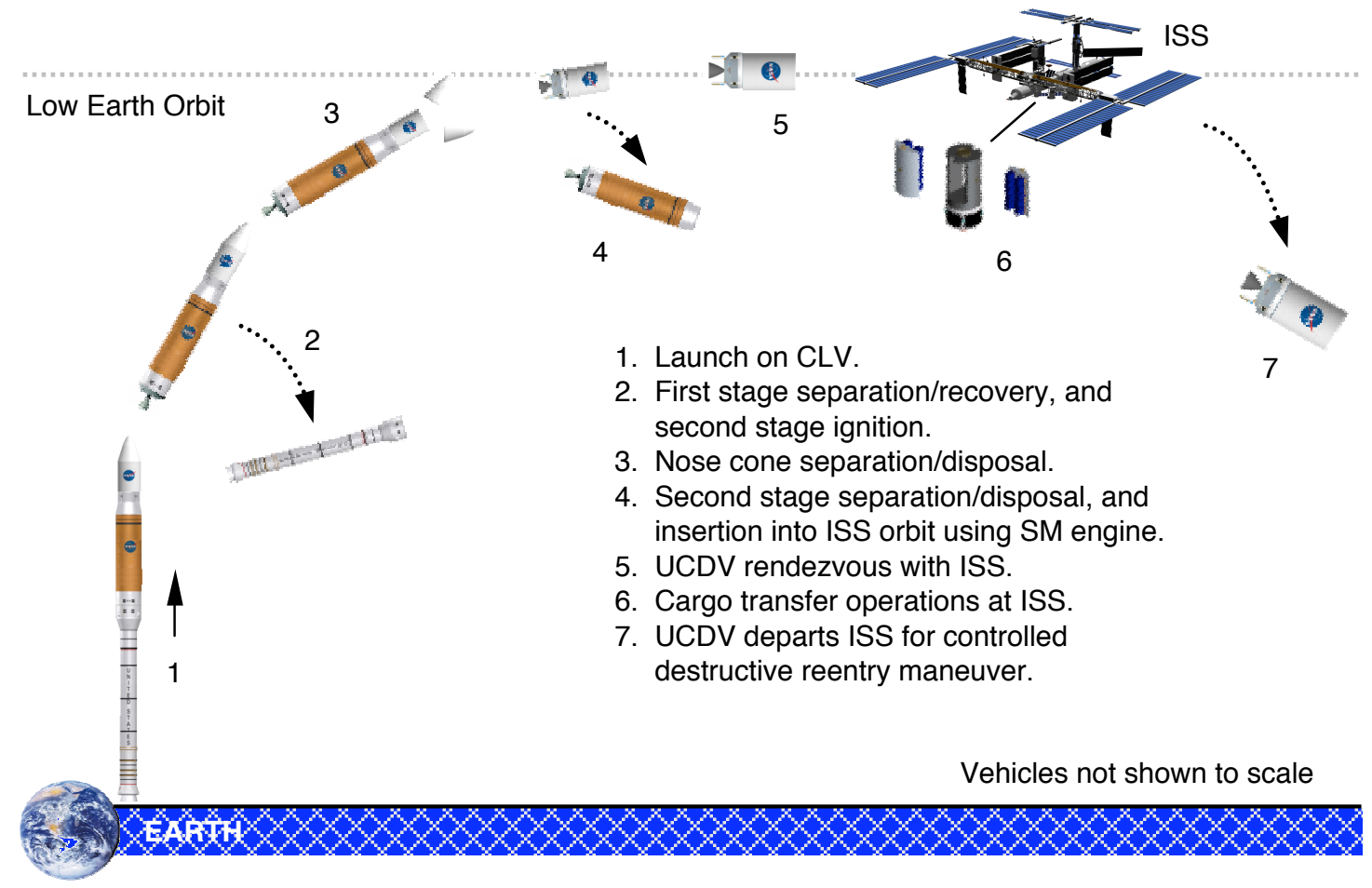

Figure 10. UCDV concept of operations. 


\section{UCDV Concept of Operations}

The UCDV concept of operations is described in this section, with the launch and in-space portions shown in Figure 10. Prior to launch, the individual ORUs are prepared for flight and integrated with their Active FRAMs in a processing facility at the NASA Kennedy Space Center. The empty cargo pallets are mounted horizontally in ground support equipment, and the Passive FRAMs are installed in their designated locations. The ORUs are then installed on the pallets in their proper locations and orientations required to satisfy mass, CM and MMOI constraints on the UCDV, CLV and ISS. The loaded cargo pallets are rotated 90 degrees to a vertical orientation and swung into their launch positions on the core structure. The mechanical latches are fastened to lock the pallets to the core structure.

After integration of the SM and nose cone, the assembled UCDV is stacked on a CLV, and the combined vehicles are rolled out to the launch pad where final flight preparations are made. The UCDV is launched on the CLV to a $30 \times 160 \mathrm{nmi}, 51.6$-degree inclination transfer orbit. While the CLV is designed with a maximum axial acceleration of $4 \mathrm{~g}$, its ascent trajectory with the UCDV spacecraft could be easily tailored to a maximum $3 \mathrm{~g}$ axial acceleration, thus maintaining compatibility with the Space Shuttle design heritage of the existing ORUs. This would eliminate the need to redesign or recertify the ORUs for the higher ascent load, but does result in a small performance penalty calculated at approximately $100 \mathrm{lbs}$ of payload.
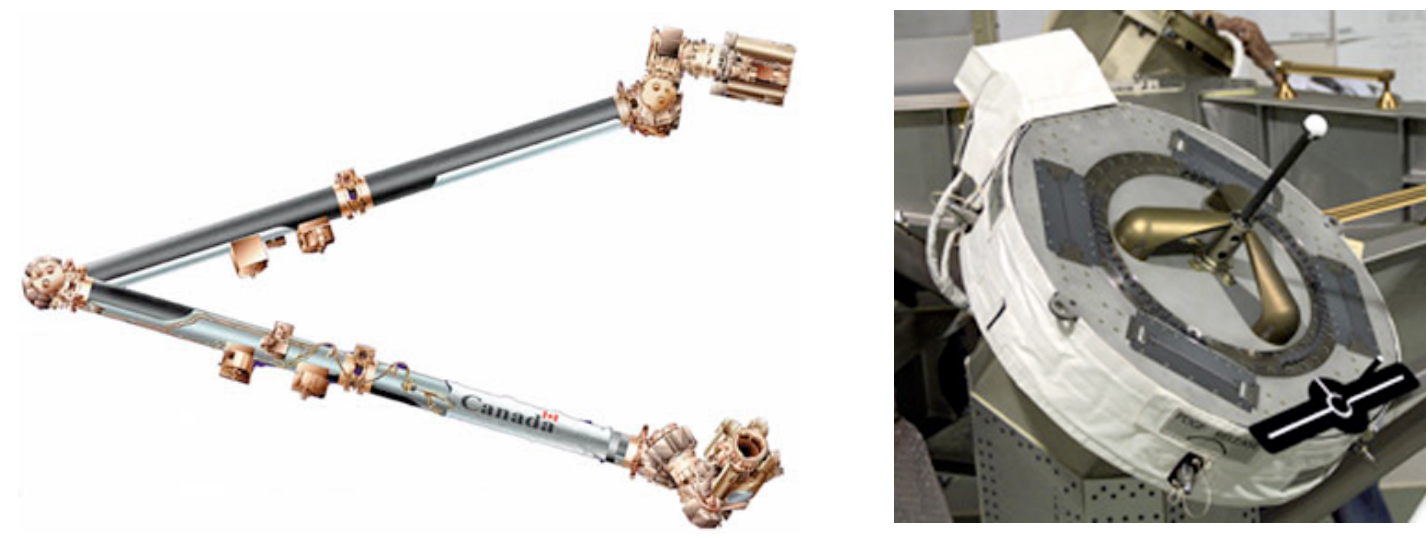

Figure 11a (left), 11b (right). SSRMS and PDGF mechanisms.

The nose cone is separated from the UCDV when the dynamic pressure becomes negligible shortly after second stage ignition. After achieving insertion into the desired transfer orbit, the UCDV separates from the second stage, which then reenters into the Pacific Ocean. The SM engine then fires to provide the remaining propulsion required to reach the ISS orbit. For rendezvous with the ISS, the UCDV approaches the ISS and enters the berthing box in a station-keeping mode, where it is captured with the Space Station Remote Manipulator System arm (shown in Figure 11a) on a Power Data Grapple Fixture (Figure 11b) mounted on the UCDM core structure.

The UCDV is then berthed to an open Active CBM port on the ISS, which also provides a power and data link between the two vehicles. Several different options for this ISS interface have been investigated that can leverage existing space-rated hardware and experience. A Passive CBM (see Figure 12a) is shown installed on the front of the UCDM in Figures 1 and 2, and several ports on the ISS are already fitted with Active CBMs. Other possible interface mechanisms shown in Figures $12 \mathrm{~b}$ and $12 \mathrm{c}$ are the Low Impact Docking System (Ref. 5) originally developed for the X-38 Crew Return Vehicle, and the Russian-built Androgynous Peripheral Attachment System (Ref. 6) used on the Space Shuttle and Soyuz spacecraft for docking to the ISS, as well as some inter-module connections on the ISS. Potential issues with these 
systems include the fact that no new CBMs are currently being produced, the relatively low development level of the LIDS, and the high dynamic forces required to engage the APAS latches.
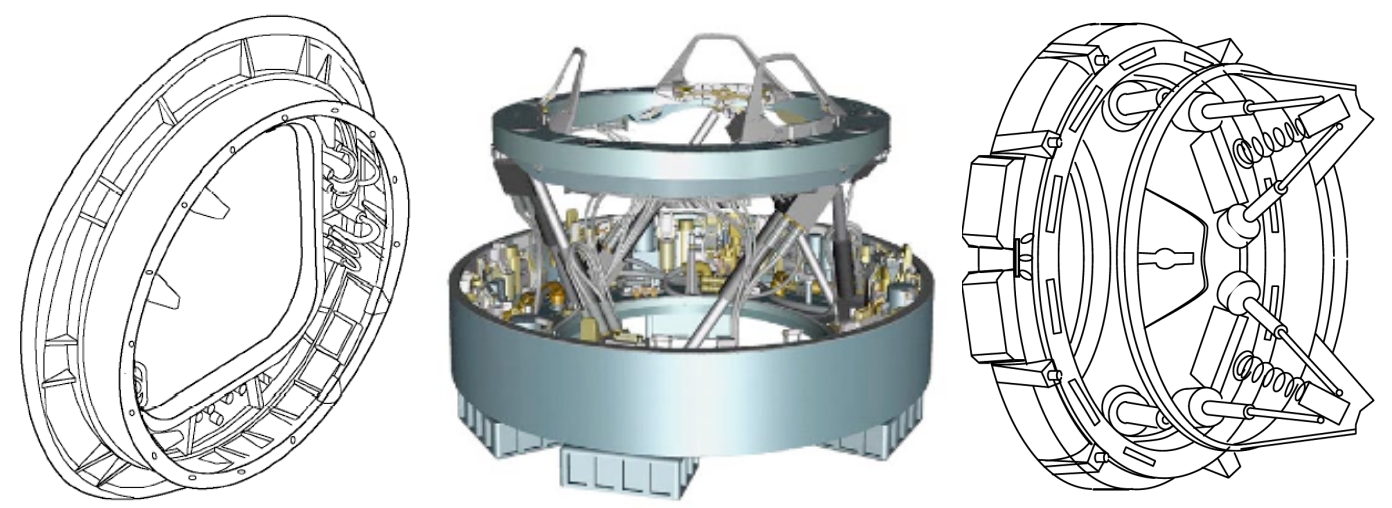

Figure 12a (left), 12b (center), 12c (right). Passive CBM, LIDS and APAS mechanisms.

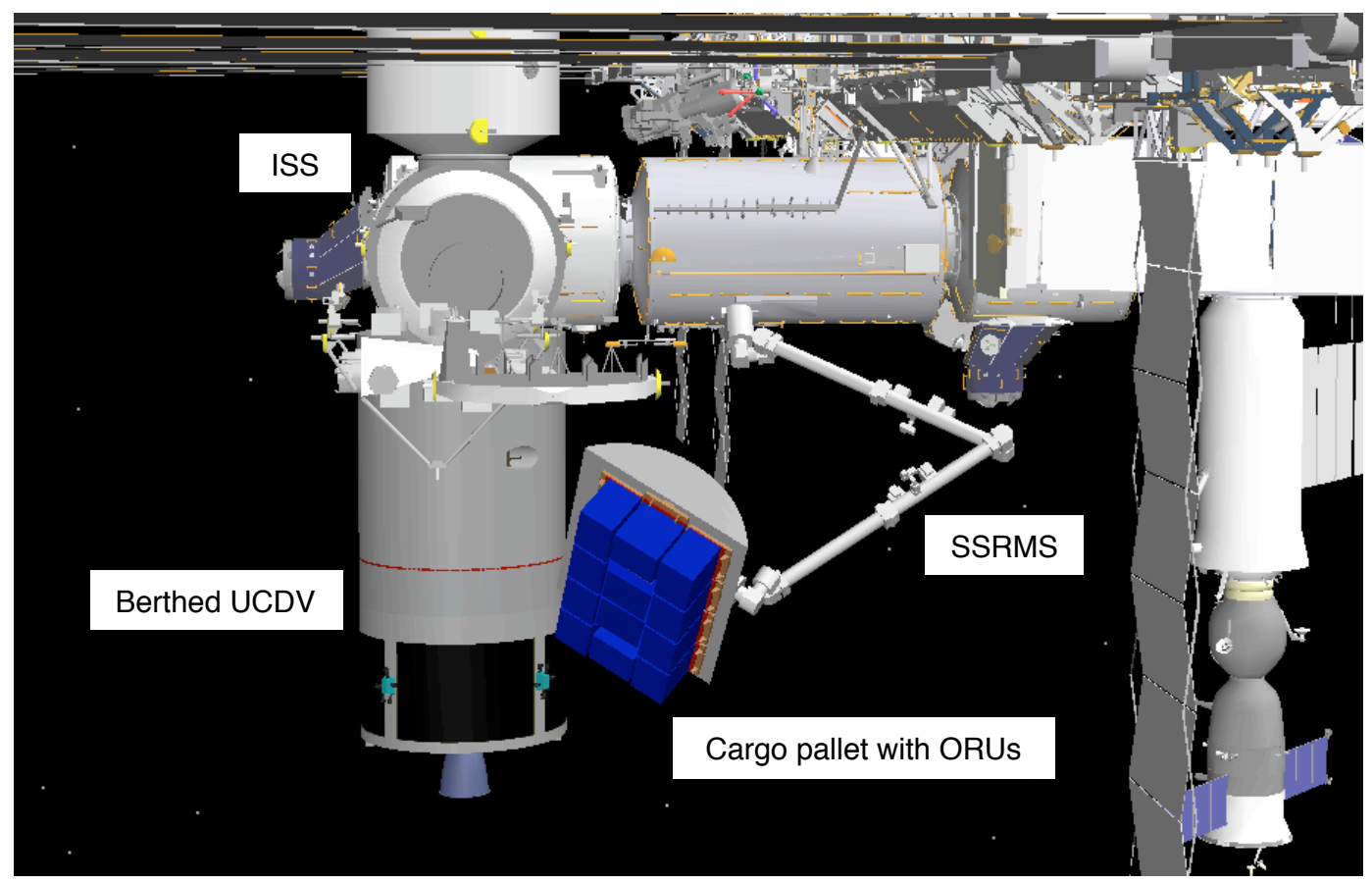

Figure 13. UCDV and cargo pallet transfer operations on ISS.

After berthing the UCDV to the ISS, one end effector on the SSRMS grapples a PDGF on the Mobile Transporter/Mobile Base System. The other SSRMS end effector then grasps a FRGF on a pallet, releases the latches, and extracts that pallet with its attached cargo from the UCDM core structure (see Figure 13). The MT/MBS with attached SSRMS and pallet then moves along the ISS truss to an unoccupied Active PAS location on either the P3 or S3 truss to stow the pallet, as shown in Figure 14. For the first UCDV flight to the ISS, the UCDM core structure and attached SM are then unberthed and deorbited, leaving two full pallets of new ORUs on the ISS. The ISS crew then removes and installs the ORUs using EVAs or the SSRMS, and then load the unserviceable ORUs back onto the stowed pallet. When a new UCDV arrives with fresh ORUs, these full pallets are removed from the UCDV and stored on the ISS. The two old pallets, now full of unserviceable ORUs, are then reattached to the newly arrived UCDV using the SSRMS and MT/MBS. The UCDV remains berthed to the ISS for a maximum of 30 
days, after which it is unberthed and departs the ISS for disposal of the vehicle and unserviceable ORUs in a controlled destructive deorbit maneuver.

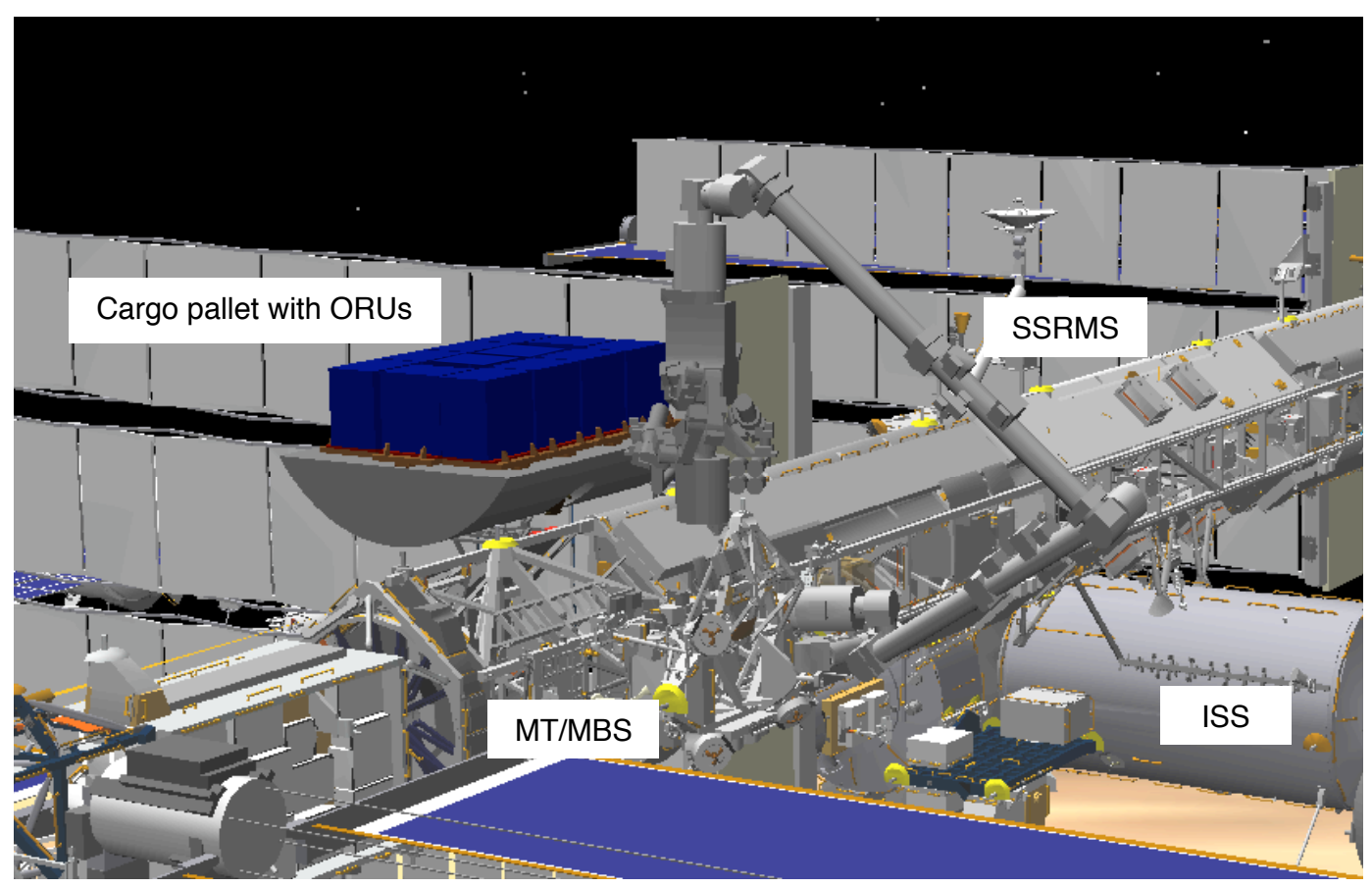

Figure 14. Cargo pallet on ISS stowage site.

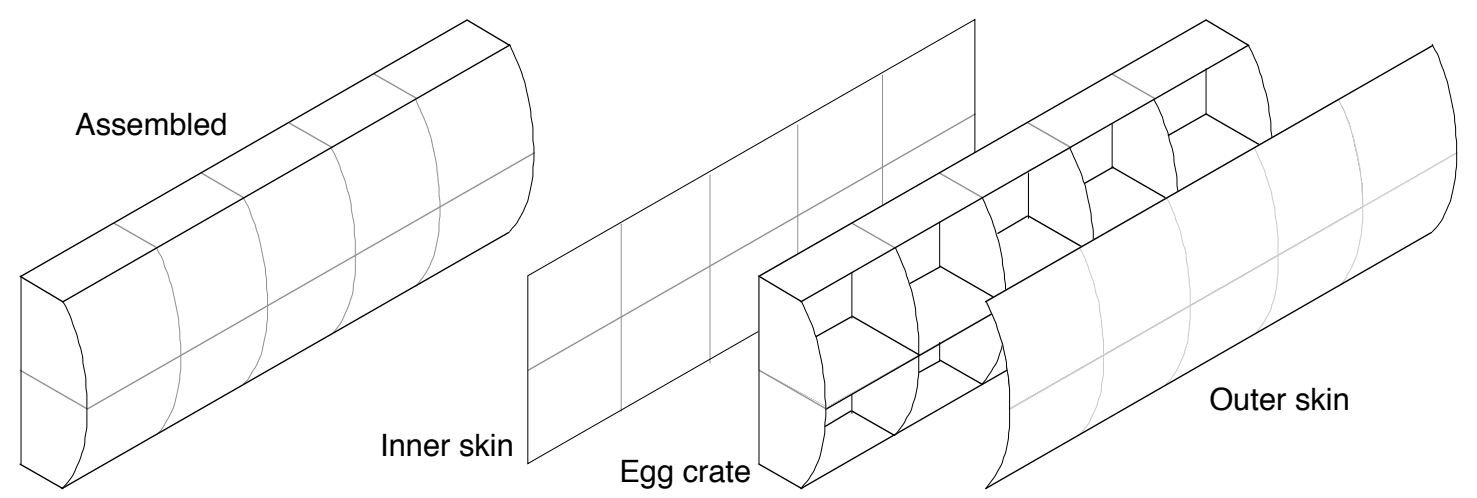

Figure 15. UCDM core beam and subcomponents.

\section{Structural Layout and Sizing}

As the vehicle layout and concept of operations were being developed, the structural configuration was also defined. Both metallic and composite structures were considered, and a graphite-epoxy composite face sheet and metallic honeycomb sandwich structure was chosen for the acreage structure. Each UCDM pallet was built up of an internal orthogonal "egg crate" structure to support the FRAM corners and core latch attachment points, and then skinned with composite sandwich panels. The box beams for the UCDM core structure were also designed in a similar fashion with internal bulkheads and cover panels. These construction methods were chosen to minimize part count and simplify fabrication. An expanded view of the core beam and major structural subcomponents is shown in Figure 15, with the cargo pallet and its subcomponents shown in Figure 16. 


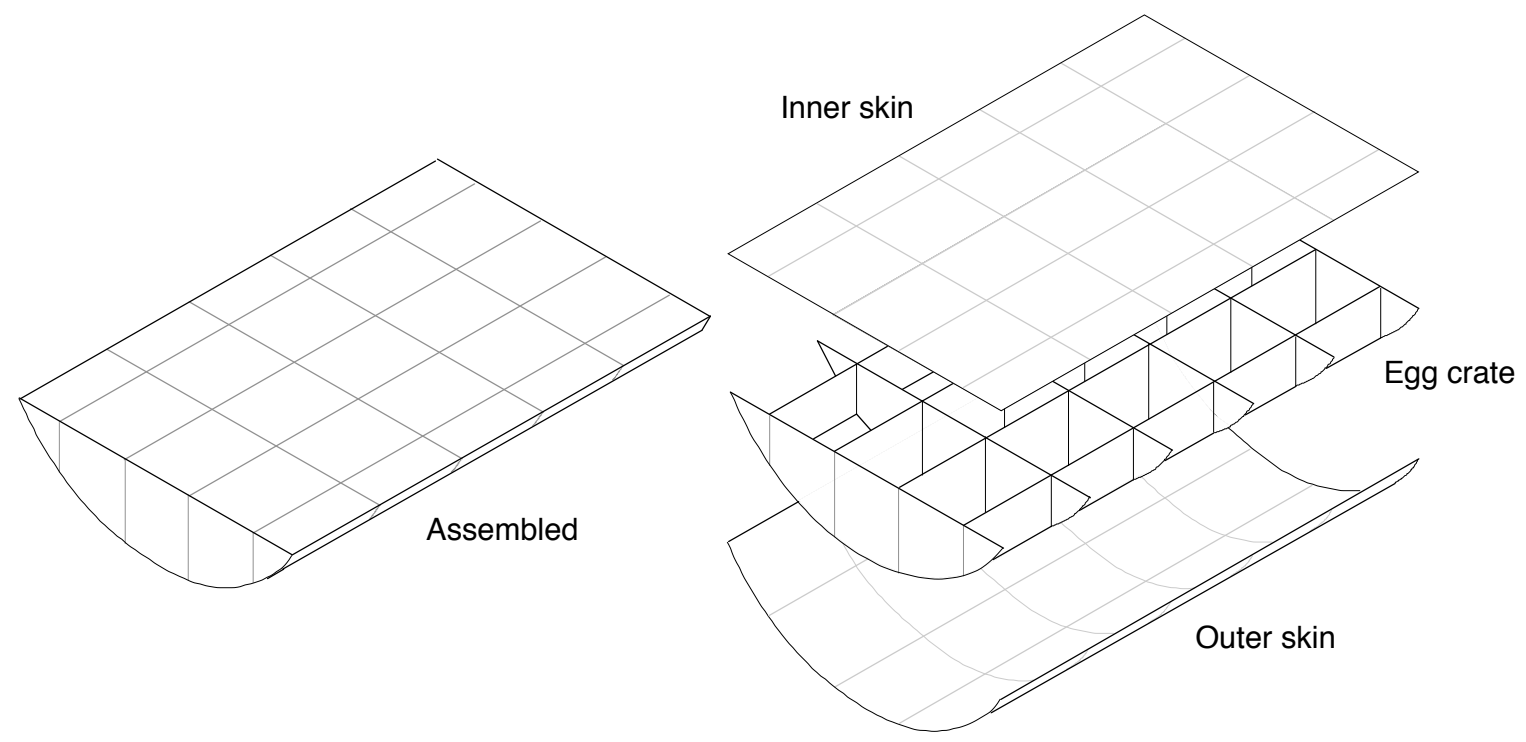

Figure 16. $(2 \times 5)$ cargo pallet structure and subcomponents.

For preliminary sizing, an areal density of $2 \mathrm{lb} / \mathrm{ft}^{2}$ is used to estimate the masses of the UCDM composite sandwich structures. This value was chosen using experience gained with a graphite-toughened bismaleimide composite and metallic honeycomb sandwich wing box (Figure 17, Ref. 7) developed for NASA's High-Speed Research program. This highly loaded structure had wing surface areal densities ranging from 2.5 to $3.2 \mathrm{lb} / \mathrm{ft}^{2}$, and $1.3 \mathrm{lb} / \mathrm{ft}^{2}$ for the spar webs. The corresponding design loads of 10 to $20 \mathrm{klb} / \mathrm{in}$. in-plane tension and compression, and $2.5 \mathrm{klb} / \mathrm{in}$. in-plane shear are plotted with their associated areal densities in Figure 18. A rough estimate of the maximum compressive load $\mathrm{Nx}$ at the UCDM/SM interface plane is computed here as the product of the largest possible mass forward of the separation plane (50.5 klb CLV performance - $15.3 \mathrm{klb}$ SM mass), the $4 \mathrm{~g}$ peak axial acceleration and a 1.25 factor of safety, all divided by the SM circumference, or

$$
\mathrm{Nx}=(35.1 \mathrm{klb} \times 4 \mathrm{~g} \times 1.25 \mathrm{FS}) /(2 \pi \times 2.75 \mathrm{~m} \times 39.37 \mathrm{in} / \mathrm{m})=258 \mathrm{lb} / \mathrm{in} .
$$

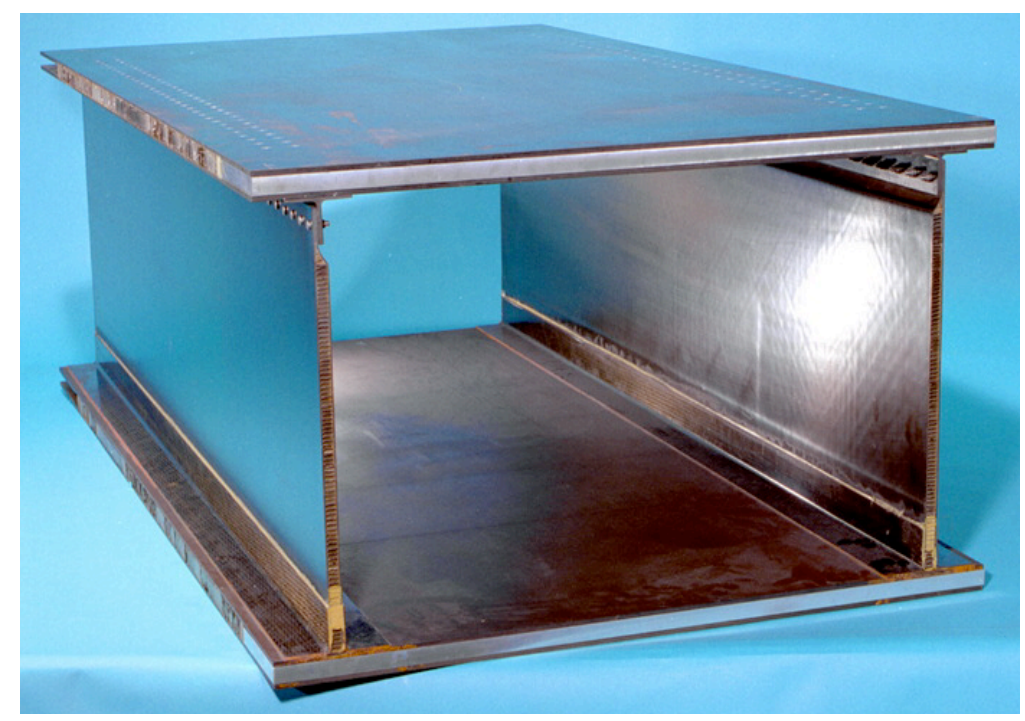

Figure 17. Composite sandwich wing box. 


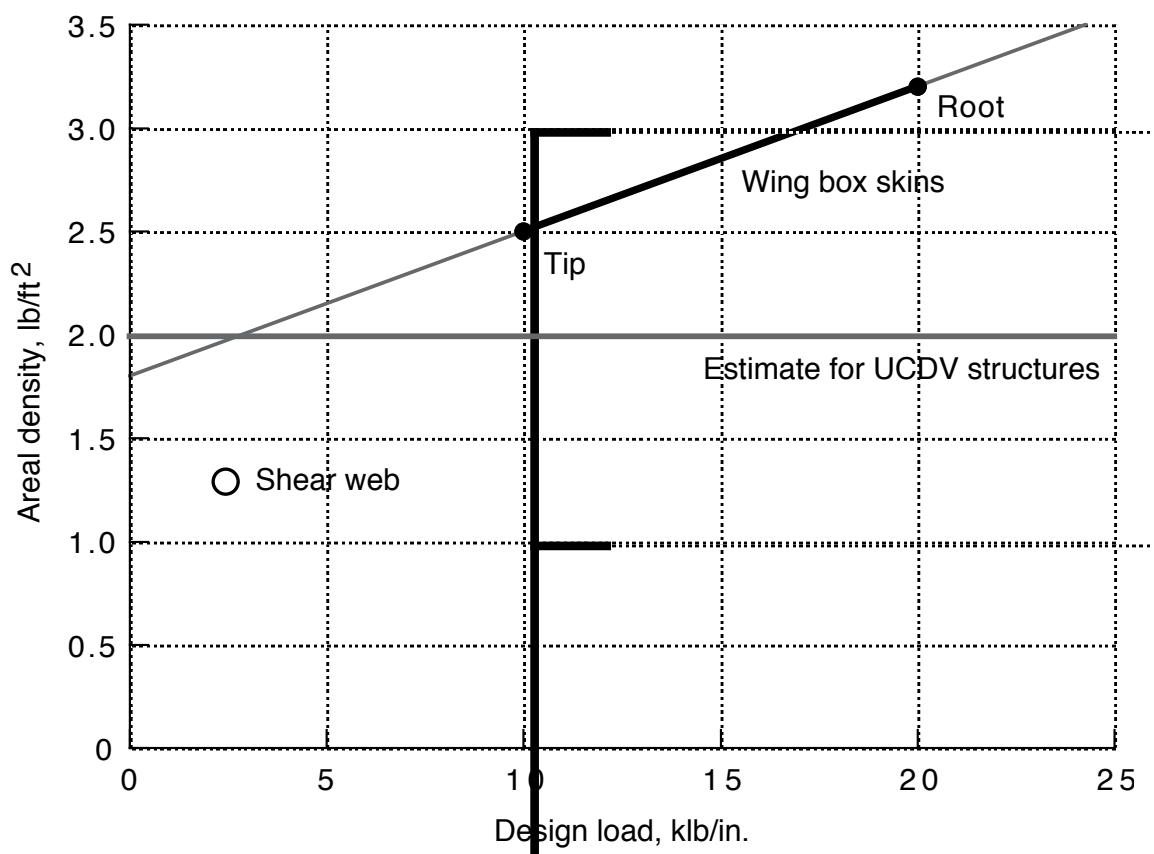

Figure 18. Wing box structural element sizing.

The result computed in Equation 1 assumes that the UCDM inertial load is evenly distributed around its circumference at the interface plane. Depending on how the loaded cargo pallets are designed to transfer their inertial loads through into the core structure, the local loads at the latches may be much higher than this estimate. However, the running load in Equation 1 is still an order of magnitude lower than the lowest wing box design load. Since the compressive loads at the UCDM/nose cone interface will be even lower due to the lower supported mass above, these results indicate that the overall UCDV structural loads should be lower than the wing box design loads.

As a point of reference to determine the validity of these high-level mass estimates, a comparison was made with the External Stowage Platform-2 payload (Ref. 8). The ESP-2 is an unpressurized logistics carrier that was delivered to the ISS on the STS-114 mission in July 2005. The dry mass of the ESP-2 flight hardware is reported as $5900 \mathrm{lbs}$, and it carries ORUs mounted on eight FRAMs. Division of these two values gives a normalized ESP-2 system mass of $738 \mathrm{lbs} /$ FRAM. Division of the 15,889 lb UCDM dry mass reported in Table 1 (and discussed in more detail in the following section on Vehicle Sizing and Performance) by 20 FRAMs gives a normalized UCDM system mass of $794 \mathrm{lbs} / F R A M$, which is within ten percent of the corresponding value for the ESP-2. Based on these estimates and the analyses described above, the $2 \mathrm{lb} / \mathrm{ft}^{2}$ areal density chosen for preliminary sizing of the UCDM may be somewhat conservative (as is appropriate at this early stage of design), and the as-built structures may prove to be lighter.

Further finite element analysis and structural sizing of the UCDM were performed using commercial software and are described in Reference 9. Various structural concepts, including both composite and metallic sandwich panels and skin-stringer constructions, were examined in this study. As expected, high local stress concentrations were noted around the discrete attachment points where the pallets connect to the core beam structure. The composite honeycomb structure was also determined to be the minimumweight construction, with an areal density well below $1 \mathrm{lb} / \mathrm{ft}^{2}$. While not surprising for this level of analysis, inclusion of practical design details such as edge close-outs and local reinforcements required to support fasteners and other point loads will tend to drive the weight higher. These design details and other considerations are typically lumped into a single "non-optimal" factor for the purposes of preliminary design studies. 


\section{Vehicle Sizing and Performance}

Using the layout described above for the UCDM, the mass of the primary vehicle structure (pallets and core beams) is estimated as 8,268 lbs. Addition of other mechanisms (Passive CBM, Passive PAS, Passive FRAMs, FRGF, PDGF, etc.) results in a total structural mass of $11,010 \mathrm{lbs}$. Addition of the various other subsystem masses yields a UCDM dry mass estimate of $13,241 \mathrm{lb}$, and 20 percent growth margin is applied to obtain a design mass with margin of $15,889 \mathrm{lb}$. The UCDM mass of $15,889 \mathrm{lb}$ is added to the $16,000 \mathrm{lb}$ payload (20 cargo units $\times 800 \mathrm{lbs}$ each), the 15,241 lb SM mass and the $2205 \mathrm{lb}$ node cone mass and performance impact, resulting in an estimate of 49,335 lbs for the complete UCDV. These mass estimates are also shown by Work Breakdown Structure element in Table 1 for the vehicle design evaluated for the ESAS. Considering the estimated CLV performance of 50,480 lbs to the $30 \mathrm{x}$ $160 \mathrm{nmi}$ ISS transfer orbit, the actual dry UDCM growth margin is just under 29 percent.

The system performance estimates presented here use the same data reported for the crewed version of the CLV in the ESAS final report. These analyses are sufficient for the conceptual level of design in this study. However, an ascent trajectory performance and loads analysis that accounts for all of the particular details of the UCDV design (aerodynamics, no LAS, maximum $3 \mathrm{~g}$ axial acceleration, nose cone separation, etc.) is still required to determine if this spacecraft design is compatible with the launch vehicle. These more detailed analyses would be required if this concept were to be matured further.

\section{Concluding Remarks}

The system requirements, vehicle configuration, concept of operations, and structural design and layout for the UCDV concept are presented in this paper. The initial concept study was performed in support of NASA's ESAS activity at the NASA Langley Research Center. The vehicle design presented in the ESAS final report can deliver 20 cargo units with a mass of $16,000 \mathrm{lb}$ to the ISS, exceeding the given requirements by 2 cargo units and $2800 \mathrm{lbs}$ of payload. Modified pallet designs can accommodate up to 24 cargo units with $19,200 \mathrm{lbs}$ of cargo, but this may exceed the launch vehicle capability. Therefore, the basic UCDV design and options investigated offer a high degree of flexibility to accommodate a wide range of future unpressurized cargo manifests.

After conclusion of the ESAS, additional design and development of the UCDV were performed at NASA Langley. However, a NASA decision to develop the ISS unpressurized cargo resupply capability within the commercial market under the Commercial Orbital Transportation Services program resulted in termination of this internal effort. Since continuing support for the ISS is a high priority for NASA, the UCDV spacecraft design presented here remains available as a fallback option to the COTS program. Despite substantial changes in the launch vehicle design from the version presented in the ESAS report, this UCDV concept is still compatible in most respects with the current Ares I launch vehicle design, performance and requirements.

\section{References}

1. Kitmacher, G., editor: Reference Guide to the International Space Station. NASA SP-2006-557, August 2006.

2. Anon.: NASA's Exploration Systems Architecture Study: Final Report. NASA/TM-2005-214062, November 2005.

3. Anon.: Flight Releasable Attachment Mechanism System Prime Item Development Specification. International Space Station Program SSP 50491, Revision B. 7 March 2005.

4. Anon.: International Space Station Familiarization Training Manual. Mission Operations Directorate, Space Flight Training Division, NASA Johnson Space Center. ISS FAM C TM 21109, 01(0)T0007, Version 1.0, June 3, 2004.

5. Lewis, J. L., et al.: Androgynous, Reconfigurable Closed Loop Feedback Controlled Low Impact Docking System with Load Sensing Electromagnetic Capture Ring. U. S. Patent 6,354,540, March 12, 2002. 
6. Anon.: Androgynous Peripheral Docking System Reference Guide. United Space Alliance, Space Flight Operations Contract. USA008876 Basic. February 14, 2005.

7. Palm, T., et al.: BMI Sandwich Wing Box Analysis and Test. Proceedings of the 41st AIAA/ASME/ASCE/AHS/ASC Structures, Structural Dynamics, and Materials Conference. Atlanta, Georgia, April 3-6, 2000. Paper number AIAA 2000-1342.

8. Anon.: External Stowage Platform-2 (ESP-2). Webpage accessed February 26, 2007 at http://www.boeing.com/defense-space/space/returntoflight/sts-114/esp-2.html

9. Martinovic, Z.: Structural Design and Analysis of Un-pressurized Cargo Delivery Vehicle. Proceedings of the 48th AIAA/ASME/ASCE/AHS/ASC Structures, Structural Dynamics, and Materials Conference. Honolulu, Hawaii, April 23-26, 2007. Paper number AIAA 2007-2370.

\begin{tabular}{|c|c|c|c|}
\hline 1.0 Structure & Quantity & $4995 \mathrm{~kg}$ & $11010 \mathrm{lb}$ \\
\hline Pallet structure (1250 kg each) & 2 & 2500 & 5512 \\
\hline Core structure & 1 & 1250 & 2756 \\
\hline Passive PAS (115 kg each) & 2 & 230 & 506 \\
\hline Passive FRAM (15 kg each) & 20 & 300 & 660 \\
\hline FRGF (2) \& PDGF (1) & 3 & 38 & 84 \\
\hline Passive CBM & 1 & 177 & 390 \\
\hline Avionics bay & 1 & 500 & 1102 \\
\hline 2.0 Protection & & $100 \mathrm{~kg}$ & $220 \mathrm{lb}$ \\
\hline Insulation & & 100 & 220 \\
\hline 3.0 Propulsion & & 0 & 0 \\
\hline 4.0 Power & & $290 \mathrm{~kg}$ & $638 \mathrm{lb}$ \\
\hline Cabling & & 290 & 638 \\
\hline 5.0 Control & & 0 & 0 \\
\hline$\underline{6.0 \text { Avionics }}$ & & $623 \mathrm{~kg}$ & $1373 \mathrm{lb}$ \\
\hline Command, control \& data handling & & 156 & 344 \\
\hline Guidance, navigation \& control & & 112 & 247 \\
\hline Communications & & 128 & 282 \\
\hline Instrumentation \& cabling & & 227 & 500 \\
\hline 7.0 Environment & & 0 & 0 \\
\hline 8.0 Other & & 0 & 0 \\
\hline 9.0 Growth Margin & & $1202 \mathrm{~kg}$ & $2648 \mathrm{lb}$ \\
\hline 20 percent & & 1202 & 2648 \\
\hline 10.0 Non-Cargo & & 0 & 0 \\
\hline 11.0 Cargo & & $7260 \mathrm{~kg}$ & $16000 \mathrm{lb}$ \\
\hline $\begin{array}{l}\text { Cargo unit (363 kg each) } \\
\text { includes ORU \& Active FRAM }\end{array}$ & 20 & 7260 & 16000 \\
\hline 12.0 Non-Propellant & & 0 & 0 \\
\hline 13.0 Propellant & & 0 & 0 \\
\hline UCDM Gross Mass & & $14470 \mathrm{~kg}$ & $31889 \mathrm{lb}$ \\
\hline SM Gross Mass & & $6912 \mathrm{~kg}$ & $15241 \mathrm{lb}$ \\
\hline Nose Cone Mass and performance impact & & $1000 \mathrm{~kg}$ & $2205 \mathrm{Ib}$ \\
\hline Total UCDV Mass & & $22382 \mathrm{~kg}$ & $49335 \mathrm{lb}$ \\
\hline CLV Performance to $30 \times 160 \mathrm{nmi}, 51.6 \mathrm{deg} .0$ & & $22900 \mathrm{~kg}$ & $50480 \mathrm{lb}$ \\
\hline
\end{tabular}

Table 1: UCDV system mass estimates. 